\title{
Produksi Selada (Lactuca sativa L.) Menggunakan Sistem Hidroponik Dengan Perbedaan Sumber Nutrisi
}

\author{
Author(s): Atika Romalasari*(1); Enceng Sobari ${ }^{(1)}$ \\ (1) Politeknik Negeri Subang \\ * Corresponding author: atika.romalasari@gmail.com
}

\begin{abstract}
ABSTRAK
Selada merupakan salah satu sayuran daun yang digemari oleh masyarakat. Selada biasanya dikonsumsi dalam bentuk segar sebagai lalapan. Peningkatan dan potensi budidaya selada menuntut adanya teknik budidaya yang efisien. Produksi suatu tanaman dengan sistem hidroponik erat kaitanya dengan ketersediaan larutan nutrisi. Penelitian ini bertujuan untuk mendapatkan informasi ilmiah tentang pertumbuhan dan hasil selada (Lactuca sativa L.) pada nutrisi berbeda secara hidroponik. Rancangan Percobaan yang digunakan adalah Rancangan Acak Kelompok (RAK) dengan satu faktor, yaitu jenis larutan nutrisi yang terdisi dari larutan nutrisi $\mathrm{AB}$ mix 1, larutan nutrisi $\mathrm{AB}$ mix 2 dan larutan nutrisi silika. Hasil penelitian yang diperoleh menyatakan bahwa larutan dengan perbedaan sumber nutrisi memberikan pengaruh yang sangat nyata pada pertumbuhan tanaman dilihat dari karakter tinggi tanaman dan berpengaruh nyata pada jumlah helai daun. Analisa $\mathrm{pH}$ dan TDS yang dilakukan untuk menggambarkan ketersediaan hara yang dapat terserap pada sumber nutrisi yang digunakan. Penggunaan larutan nutrisi $\mathrm{AB}$ mix 1 dan larutan nutrisi $\mathrm{AB}$ mix 2 dinilai lebih efisien dalam mempengaruhi produksi selada dibandingkan penggunaan larutan nutrisi silika.
\end{abstract}

Kata Kunci:

$\mathrm{AB}$ mix;

Hidroponik;

Nutrisi;

Selada;

Silika;

$\begin{array}{ll}\text { Keywords: } & \text { Lettuce is one of the leaf vegetables favored by the community. Lettuce is usually } \\ \text { AB mix; } & \text { consumed as fresh vegetables. The increase and potential of lettuce cultivation requires } \\ \text { efficient cultivation techniques. The production of a plant with a hydroponic system is } \\ \text { Hydroponic; } & \text { closely related to the availability of nutrient solutions. This experiment aims to obtain } \\ \text { Scientific information about the growth and yield of lettuce (Lactuca sativa L.) in } \\ \text { different nutrients. The design experiment that used was Randomized Block Design } \\ \text { Nutrition; } & \text { (RBD) with one factor, namely the type of nutrient solution, which consists AB mix } 1 \\ \text { Silica; } & \text { nutrient solution, AB mix } 2 \text { nutrient solution and silica nutrient solution. The results } \\ & \text { obtained showed that the solution of differences in nutrient sources had a very significant } \\ & \text { effect on plant growth seen from the character of plant height, and significant influence } \\ & \text { on the number of leaflets. Observation on pH and TDS clarify the availability of nutrients } \\ & \text { that can be absorbed in the source of nutrients used. The use of AB mix } 1 \text { nutrient solution } \\ \text { and AB mix } 2 \text { nutrient solution were considered more efficient in influencing lettuce } & \text { production compared to the use of silica nutrient solution. }\end{array}$




\section{PENDAHULUAN}

Selada merupakan salah satu sayuran daun yang digemari oleh masyarakat. Selada biasanya dikonsumsi dalam bentuk segar sebagai lalapan. Restoran-restoran serta hotel juga menggunakan selada dalam masakannya, misalnya salad, hamburger, dan gado-gado. Selada memiliki berbagai kandungan gizi, seperti serat, vitamin A, dan mineral. Kandungan gizi pada sayuran terutama vitamin dan mineral tidak dapat disubstitusi oleh makanan pokok. Seiring dengan peningkatan jumlah penduduk serta kesadaran masyarakat terhadap nilai gizi dan manfaat kesehatan maka permintaan konsumen terhadap selada semakin meningkat.

Peningkatan permintaan ini menuntut adanya peningkatan produksi. Namun, kondisi alam dan luasan lahan produksi kadang menjadi kendala dalam kegiatan budidaya sayuran. Peningkatan produksi tanaman dapat dilakukan dengan teknik budidaya yang memiliki efisiensi dan efektivitas yang tinggi. Teknik budidaya secara hidroponik merupakan salah satu upaya intensifikasi yang pada akhirnya akan meningkatkan efisiensi dan efektivitas dalam penggunaan lahan dan penggunaan larutan nutrisi (Ardian, 2007).

Hidroponik merupakan teknik budidaya tanaman yang menggunakan air sebagai medium tanamnya yang mengandung nutrisi dan oksigen dalam kadar tertentu. Menurut Susila (2017) hidroponik merupakan teknik budidaya tanaman dalam lingkungan terkendali, tanpa tanah, dengan pemberian hara tanaman yang terkendali, serta dapat dilaksanakan menggunakan substrate maupun tanpa substrate. Terdapat beberapa teknik dalam menerapkan budidaya sayuran secara hidroponik, diantaranya yaitu teknik hidroponik sistem terapung Susila and Koerniawati (2004) Nutrient Film Technique (NFT), dan aeroponik (Smith, 2005).
Pada awalnya sistem hidroponik identik dengan penanaman tanpa media tanah, akan tetapi sesuai dengan perkembangan teknologi, hidroponik digunakan untuk penumbuhan tanaman dengan mengontrol nutrisi tanaman sesuai dengan kebutuhannya. Larutan unsur hara atau nutrisi sebagai sumber pasokan air dan mineral merupakan faktor yang sangat penting untuk pertumbuhan dan kualitas hasil tanaman pada budidaya sistem hidroponik. Namun pemberian larutan nutrisi pada tanaman hidroponik ini harus diperhatikan jenisnya dan diperlukan kontrol yang tepat. Pemberian kadar nutrisi yang tidak sebanding dengan kebutuhan tanaman mengakibatkan tanaman kerdil, daun menguning dan gugur sehingga tanaman tidak saling menaungi satu sama lain dan luas daun tanaman rendah (Indrawati, Indradewa, \& Utami, 2012).

Percobaan ini bertujuan untuk mendapatkan informasi ilmiah tentang pertumbuhan dan hasil selada (Lactuca sativa L.) pada nutrisi berbeda secara hidroponik.

\section{BAHAN DAN METODE}

Percobaan dilaksanakan dari pada bulan Juli hingga Agustus 2018, bertempat di areal Politeknik Negeri Subang. Bahanbahan yang digunakan dalam Percobaan antara lain adalah benih selada Grand Rapids, air, rockwool, larutan nutrisi $\mathrm{AB}$ mix 1, larutan nutrisi AB mix 2, dan larutan nutrisi Silika serta bahan pembuatan set rangkaian hidroponik. Alat-alat yang digunakan antara lain wadah persemaian (tray), hand sprayer, mistar, EC/TDS meter, $\mathrm{pH}$ meter.

Rancangan Percobaan yang digunakan adalah Rancangan Acak Kelompok (RAK) dengan satu faktor, yaitu jenis larutan nutrisi. Perlakuan yang akan diberikan adalah sebanyak tiga perlakuan, dimana masing-masing perlakuan terdiri dari tiga ulangan, sehingga terdapat 9 satuan percobaan. Jumlah tanaman contoh 
yang diambil sebanyak tiga tanaman untuk setiap satu satuan percobaan. Perlakuan dalam Percobaan adalah sebagai berikut : $\mathrm{P} 1$ : Aplikasi larutan nutrisi $\mathrm{AB}$ mix 1, P2 :Aplikasi larutan nutrisi $\mathrm{AB}$ mix 2, P3 : Aplikasi larutan nutrisi Silika $\left(\mathrm{SiO}_{3}\right)$.

Pelaksanaan Percobaan dimulai dari kegiatan persemaian. Persemaian benih selada dilakukan dalam wadah persemaian berukuran Panjang $40 \mathrm{~cm}$ dan lebar $30 \mathrm{~cm}$ dengan jumlah lubang 98 yang mempunyai kedalaman $5 \mathrm{~cm}$. Benih selada disemai pada media rockwool selama 14 hari kemudian dipindahkan kedalam net pot untuk dilakukan penanaman. Penanaman dilakukan dengan memindahkan tanaman beserta net pot kedalam lubang rangkaian hidroponik. Penanaman dilakukan selama 20 hari hingga dapat dipanen. Sistem hidroponik yang dipakai menggunakan sistem NFT (Nutrient Film Technique) dimana larutan nutrisi dicampurkan ke dalam box penampung air dengan kapasitas $30 \mathrm{~L}$ dan dipompakan ke rangkaian hidroponik. Pembuatan larutan nutrisi $\mathrm{AB}$ mix dan larutan nutrisi silika dilakukan dengan cara melarutkan larutan nutrisi $\mathrm{AB}$ mix cair sebanyak $150 \mathrm{ml}$ dicampurkan kedalam $30 \mathrm{~L}$ air kemudian diaduk hingga tercampur rata dan untuk larutan nutrisi silika cair sebanyak $30 \mathrm{ml}$ dicampurkan kedalam $30 \mathrm{~L}$ air kemudian diaduk hingga tercampur rata. Karakter pengamatan pada percobaan ini antara lain: tinggi tanaman dan jumlah helai daun yang diukur pada 5-20 HST, pengukuran kandungan nutrisi larutan hidropodik pada 0, 10 dan 20 HST menggunakan metode TDS serta pengukuran $\mathrm{pH}$ pada 0,10 dan 20 HST dengan $\mathrm{pH}$ meter.

Model rancangan percobaan yang digunakan adalah sebagai berikut :

$\mathbf{Y i j}=\boldsymbol{\mu}+\mathbf{a ́ i}+\mathbf{a ̂ i}+\mathbf{a} \mathbf{i j}$

Keterangan :

Yij= Pengamatan pada perlakuan larutan nutrisi ke - i dan kelompok ke - j

$\mu=$ Rataan umum pengamatan

ái = Pengaruh larutan nutrisi pada taraf $\mathrm{ke}-\mathrm{i}$

âi $=$ Pengaruh kelompok pada taraf $\mathrm{ke}-\mathrm{j}$

åij = Galat percobaan

Pengaruh perlakuan dapat diketahui dengan menggunakan uji $\mathrm{F}$ pada taraf $1 \%$ dan 5\%. Setiap perlakuan dibandingkan dengan menggunakan uji lanjut Duncan Multiple Range Test (DMRT) pada taraf kesalahan $1 \%$ dan 5\% apabila terdapat pengaruh nyata terhadap peubah yang diamati.

\section{HASIL DAN PEMBAHASAN}

Hasil percobaan menunjukkan bahwa perbedaan larutan nutrisi dapat mempengaruhi pertumbuhan tanaman yakni pada karakter tinggi tanaman dan jumlah helai daun yang dapat terlihat pada Tabel 1 dan Tabel 2.

Tabel 1. Pengaruh perbedaan sumber nutrisi terhadap tinggi tanaman selada

\begin{tabular}{lcccc}
\hline \multirow{2}{*}{ Perlakuan } & \multicolumn{4}{c}{ Tinggi Tanaman $(\mathrm{cm})$} \\
\cline { 2 - 5 } & 5 HST & 10 HST & 15 HST & 20 HST \\
\cline { 2 - 5 } Larutan nutrisi ABMix 1 & 5.31 & 8.99 & 12.43 & 15.95 \\
Larutan nutrisi ABMix 2 & 5.53 & 9.33 & 13.67 & 16.16 \\
Larutan nutrisi Silika & 4.86 & 7.68 & 11.92 & 14.70 \\
\hline Respon & $* *$ & $* *$ & $* *$ & $* *$ \\
\hline
\end{tabular}


Berdasarkan Tabel 1, tinggi tanaman memberikan pengaruh berbeda sangat nyata. Tanaman tertinggi pada 5-20 HST terdapat pada perlakuan larutan nutrisi ABMix 2 kemudian diikuti oleh perlakuan larutan nutrisi ABMix 1, perlakuan larutan nutrisi silika memberikan respon tinggi tanaman yang paling rendah pada 5-20 HST.

Tabel 2. Pengaruh perbedaan sumber nutrisi terhadap jumlah helai daun selada

\begin{tabular}{lcccc}
\hline \multirow{2}{*}{ Perlakuan } & \multicolumn{4}{c}{ Jumlah Helai Daun } \\
\cline { 2 - 5 } & 5 HST & 10 HST & 15 HST & 20 HST \\
\cline { 2 - 5 } Larutan nutrisi ABMix 1 & 10.61 & 12.94 & 14.28 & 17.11 \\
Larutan nutrisi ABMix 2 & 10.61 & 12.44 & 15.00 & 16.89 \\
Larutan nutrisi Silika & 9.17 & 11.11 & 13.11 & 15.11 \\
\hline Respon & $*$ & $*$ & $*$ & $*$ \\
\hline
\end{tabular}

Berdasarkan Tabel 2, jumlah helai daun memberikan pengaruh berbeda nyata. Jumlah helai daun perlakuan larutan nutrisi ABMix 1 dan larutan nutrisi ABmix 2 pada 5 HST memiliki jumlah yang lebih banyak dibandingkan pada perlakuan larutan nutrisi silika. Sementara pada 10-20 HST jumlah helai daun antara perlakuan larutan nutrisi ABMix 1 dan larutan nutrisi ABMix 2 saling bergantian memberikan jumlah helai daun terbanyak. Pada 10-20 HST perlakuan larutan nutrisi silika menghasilkan jumlah helai daun yang paling sedikit.

Pada tanaman yang ditanam dengan cara hidroponik tanaman dapat berkembang dengan baik dalam larutan nutrisi sebagai pengganti tanah dimana tanaman menerima oksigen dan semua komposisi yang tidak meracuni. Komposisi dari larutan nutrisi menjadi hal yang penting dalam menentukan pertumbuhan tanaman. Silviana et al. (2009) menyatakan bahwa tanaman telah diketahui memerlukan adanya unsur hara makro dan mikro bagi pertumbuhannya. Apabila salah satu unsur hara baik makro maupun mikro kurang tersedia maka dapat menyebabkan pertumbuhan dan perkembangan tanaman terhambat. Larutan nutrisi ABMix 1 dan Larutan nutrisi ABMix 2 dinilai memiliki kandungan nutrisi yang lebih lengkap baik ketersediaan unsur makro maupun mikronya.

Larutan nutrisi silika yang dipergunakan menghasilkan pengaruh pertumbuhan baik tinnggi tanaman maupun jumlah helai daun yang rendah karena tidak mampu mencukupi unsur makro dan unsur mikro yang harus terpenuhi untuk pertumbuhan tanaman.

Fitriani and Haryanti (2016) menyatakan bahwa larutan nutrisi silika berperan sebagai hara stimulator yang baik bagi tanaman sehingga bermanfaat bagi pertumbuhan tanaman, mampu mengurangi kerobohan tanaman, menekan laju transpirasi sehingga efisien dalam penggunaan air dan lebih tahan terhadap kekeringan. Sehingga penggunaan larutan nutrisi silika akan memberikan pengaruh pertumbuhan tanaman yang baik apabila dikombinasikan dengan penggunaan larutan nutrisi lain yang telah tercukupi unsur makro dan mikronya.

Rambe (2013) juga menyatakan bahwa ketersediaan unsur hara merupakan hal yang sangat penting bagi pertumbuhan dan perkembangan tanaman, karena kandungan unsur hara akan membantu memperlancar proses metabolisme tanaman diantaranya proses fotosintesis sehingga fotosintat yang dihasilkan tinggi, yang selanjutnya dapat ditranslokasikan ke seluruh bagian tanaman. 
Nilai $\mathrm{pH}$ dalam sistem hidroponik penting untuk mengendalikan ketersediaan garam mineral. Hasil pengukuran $\mathrm{pH}$ selama percobaan dapat dilihat di Tabel 3.

Tabel 3. Nilai $\mathrm{pH}$ larutan nutrisi selama percobaan

\begin{tabular}{lccc}
\hline \multirow{2}{*}{ Perlakuan } & \multicolumn{3}{c}{$\mathrm{pH}$} \\
\cline { 2 - 4 } & 0 HST & 10 HST & 20 HST \\
\hline Larutan nutrisi ABMix 1 & 6.7 & 6.0 & 5.8 \\
Larutan nutrisi ABMix 2 & 6.7 & 6.3 & 6.6 \\
Larutan nutrisi Silika & 10.9 & 9.8 & 9.6 \\
\hline
\end{tabular}

pH larutan nutrisi dari perlakuan ABmix 1 pada 0-20 HST berada pada rentang 5.8-6.7, dan pada perlakuan larutan nutrisi ABmix 2 pada 0-20 HST berada pada rentang 6.3-6.7 sementara pada perlakuan larutan nutrisi silika nilai $\mathrm{pH}$ larutan nutrisi berada pada rentang 9.610.9. Peningkatan serapan hara atau nutrisi dipengaruhi oleh $\mathrm{pH}$, untuk tanaman selada yang baik dibutuhkan $\mathrm{pH}$ 6.0-8.0. Hal ini juga didukung oleh penelitian yang telah dilakukan oleh Adams et al., (2008) yang menyatakan bahwa kisaran $\mathrm{pH}$ untuk tanaman selada dalam sistem hidroponik berkisar antara 5.6-6.0. Kondisi larutan nutrisi pada perlakuan larutan nutrisi silika yang cenderung basa merupakan salah satu penyebab rendahnya produktivitas tanaman selada yang dihasilkan.

Nilai EC TDS menunjukkan kemampuan suatu larutan untuk menghantarkan listrik dan merupakan indikator ketersediaan suatu hara yang dapat diserap. Nilai EC TDS dari percobaan dapat dilihat pada Tabel 4 .

Tabel 4. Nilai TDS larutan nutrisi selama percobaan

\begin{tabular}{lccc}
\hline \multirow{2}{*}{ Perlakuan } & \multicolumn{3}{c}{ TDS (ppm) } \\
\cline { 2 - 4 } & 0 HST & 10 HST & 20 HST \\
\hline Larutan nutrisi ABMix 1 & 1166 & 2124 & 1766 \\
Larutan nutrisi ABMix 2 & 1726 & 2843 & 2646 \\
Larutan nutrisi Silika & 128 & 123 & 178 \\
\hline
\end{tabular}

Nilai EC TDS dari ketiga perlakuan terlihat fluktuatif dari 0-20 HST. Menurut Susila and Koerniawati (2004) kosentrasi larutan nutrisi cenderung semakin menurun dengan bertambahnya umur tanaman karena terjadinya penyerapan unsur hara. Sedangkan menurut Setiawan and Susila (2007) terjadinya fluktuasi nilai TDS yang tidak selalu menurun dipengaruhi oleh adanya ion-ion tertentu dalam larutan dan proses evapotranspirasi dari larutan nutrisi. Nilai TDS mengambarkan ketersediaan hara dari larutan nutrisi yang dapat dipergunakan oleh tanaman. Nilai TDS dari larutan nutrisi silika terbilang sangat rendah dibandingkan dengan nilai TDS yang diperoleh dari perlakuan larutan nutrisi ABMix 1 dan ABMix 2 yaitu bernilai 123$178 \mathrm{ppm}$. Menurut Nurfinayati and Susila (2004) didapatkan hasil bahwa tanaman selada dapat tumbuh baik pada TDS 250$320 \mathrm{ppm}$.

DAFTAR PUSTAKA

Adams, C. R., Bamford, K. M., \& Early, EQ M. P. (2008). Principles of Horticulture (5th ed.). https://doi.org/10.4324/9780080942 964 
Ardian. (2007). Pertumbuhan dan Hasil

琙 Tanaman Cabai Pada Berbagai Tipe Emitter dan Formulasi Nutrisi Hidroponik. Dinamika Pertanian, 22(3), 195-200.

Fitriani, H. P., \& Haryanti, S. (2016).

钢 Pengaruh Penggunaan Pupuk Nanosilika Terhadap Pertumbuhan Tanaman Tomat (Solanum lycopersicum) Var. Bulat. Buletin Anatomi dan Fisiologi, 24(1), 34-41.

Indrawati, R., Indradewa, D., \& Utami, S. N. H. (2012). Pengaruh Komposisi Media Dan Kadar Nutrisi Hidroponik Terhadap Hasil Tomat (Lycopersicon esculentum Mill.). Vegetalika, 1(3).

Iva Nur Silviana, Kadek Rachmawati, 尌 Mochammad Amin Alamsjah. (2019). Pengaruh Kombinasi Pupuk Kompos Dan NPK Terhadap Pertumbuhan, Jumlah Klorofil A Dan Kadar Air Gracilaria verrucosa [Effect Of Compost And NPK Fertilizer Combinations On Growth, Chlorophyll A And Water Content Of Gracilaria verrucose]. Jurnal Ilmiah Perikanan dan Kelautan, 1(2), 169.

https://doi.org/10.20473/jipk.v1i2.1 1685

Nurfinayati, \& Susila, A. D. (2004). 尌 Pemanfaatan Berulang Larutan Nutrisi Pada Budidaya Selada (Lactuca sativa L.) Dengan Teknologi Hidroponik Sistem Terapung (TSHS) (Skripsi, Institut Pertanian Bogor).

Rambe, M. Y. (2013). Penggunaan Pupuk 尌 Kandang Ayam dan Pupuk Urea Terhadap Pertumbuhan dan Hasil Tanaman Selada (Lactuca sativa L.) di Media Gambut (Skripsi).
Universitas Islam Negeri Sultan Syarif Kasim Riau Pekanbaru.

Setiawan, L., \& Susila, A. D. (2007). 期 Optimasi Konsentrasi Larutan Hara Pada Budidaya Selada (Lactuca sativa var. Grand Rapids) Dengan Teknologi Hidroponik Sistem Terapung (THST) (Skripsi, Institut Pertanian Bogor).

Smith, J. (2005). Hydroponics: A Practical 顽 guide for the Soilless Grower. HortTechnology, 731. https://doi.org/10.21273/HORTTEC H.15.3.0731

Susila, A. D. (2017). Teknologi Hidroponik E Sistem Terapung. Retrieved from http://anasdsusila.staff.ipb.ac.id/files /2018/01/Pengembangan-HeadLettuce-THST.pdf

Susila, A. D., \& Koerniawati, Y. (2004). E Pengaruh Volume dan Jenis Media Tanam pada Pertumbuhan dan Hsil Tanaman Selada (Loctuca sativa) dalam Teknologi Hidroponik Sistem Terapung. Jurnal Agronomi Indonesia (Indonesian Journal of Agronomy), 32(3), 16-21. 